\title{
Analyzing Complex Predicates in Karo Language using Syntactic Parsing
}

\author{
Karisma Erikson Tarigan ${ }^{1}$ (D) $\triangle$ and Margaret Stevani ${ }^{2}$ (D) \\ ${ }^{12}$ Fakultas Pendidikan Bahasa Inggris, Universitas Katolik Santo Thomas Sumatera Utara, Indonesia
}

Corresponding Author: Karisma Erikson Tarigan, E-mail: erick_tarigan2006@yahoo.com

\begin{tabular}{|c|c|}
\hline ARTICLE INFO & ABSTRACT \\
\hline $\begin{array}{l}\text { Received: June 08, } 2021 \\
\text { Accepted: July 02, } 2021 \\
\text { Volume: } 1 \\
\text { Issue: } 1 \\
\text { DOI: } 10.32996 / \text { ijls.2021.1.1.1 }\end{array}$ & $\begin{array}{l}\text { This study characterized the complex predicate and multiple events where the multi-verb } \\
\text { single clause realises a single event in syntax and examined the complex sentences } \\
\text { containing multiple verbal predicates. This study used the descriptive qualitative method. } \\
\text { The data sources used were sentences containing karo sentence clauses and was classified } \\
\text { based on the elements of complex Predicates in a tree diagram and the RRG account of } \\
\text { nexus-juncture relations theory by Nolan, } 2005 \& \text { Van Valin, 2005. The findings showed }\end{array}$ \\
\hline $\begin{array}{l}\text { Complex predicate, Karo } \\
\text { language, Tree diagram, Nexus- } \\
\text { juncture relation }\end{array}$ & $\begin{array}{l}\text { that event, argument, and semantic could be realized in syntactic meaning to reveal } \\
\text { complex predicates. The tightest syntactic linkages embodied the closer semantic relations } \\
\text { and it was signaled by word order. Most of the complex predicates in Karo language have } \\
\text { an embedded object. The core in the nucleus could be appeared not only as one core but } \\
\text { two or more complex predicates and it followed by an argument with the form V+V+N and } \\
\text { in the form of } \mathrm{V}+\mathrm{V}+\mathrm{N} \text {. One argument (Participant/Actor) that involved one core. It assumed } \\
\text { that there might be one participant in two events, and there may be two participants in one } \\
\text { event. All of Karo language sentences have at least one NP + one VP and they consisted of } \\
\text { more than one complex predicates. }\end{array}$ \\
\hline
\end{tabular}

\section{Introduction}

Complex predicates and multi-verb constructions in a wide range of languages have complex event argument realization and syntactic variation. Many different definitions of multi-verb constructions exist in the literature and it is clear that there is no unified consensus on the characteristics of these in the world's language. Bril (2007) posits several criteria as diagnostics of complex predicates that are applicable cross-linguistically. The criteria of complex predicates are; a) they comprise a sequence of predicates constituting one single predication. b) They share the same tense, aspect, mood (marked on one or all verbs of the sequence) or, if not the same marker, a set of closely dependent mood markers; they share the same illocutionary force and polarity (all predicates fall under the scope of negation marker). C) They are lexically autonomous predicates with predicate semantics. D) they do not evidence any loss of morph-syntactic properties, nor any loss of stress pattern or phonological form. Complex predicates allow two or more predicational elements to co-predicate in a mono-clausal structure. The structure is central to the study of syntax. But the structure is a very general concept that applies to any complex thing. When we say something is complex, we mean, not that it is complicated but that: 1) it's divisible into parts (its Constituent), 2) there are different kinds of parts (different categories of constituent), 3) the constituents are arranged in a certain way, 4) and each constituent has a specifiable function in the structure of the thing as a whole (Burton-roberts, 2016:23).

In a sentence or clause with multiple verbs, the multiple verbs are argued to represent individual discrete events characterized in some relational significance and conceptualized as forming a cognitive unit with significant syntactic consequences for argument realization and argument sharing. The complexity of mapping from events requires us to start within a situation, from event-

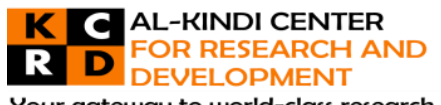

Your gateway to world-class research

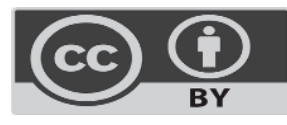

Published by Al-Kindi Center for Research and Development. Copyright (c) the author(s). This open access article is distributed under a Creative Commons Attribution (CC-BY) 4.0 license 
specific participants, to develop a model of how the semantics of those participant roles motivate the grammatical patterns found in argument realization.

According with Nolan and Diedrichsen (2017:15) stated that each event is syntactically represented by verb. A single Verb may be represented by a sequence of verbs where one of the verbs reflects either an event phase or sub-event component of a single holistic event. A situation is conceived of as a cognitive frame, referring to one or more events and the participants that play a role within the events. As a framing mechanism, a situational perspective has the advantage of making explicit the semantic and syntactic behaviours across complex events and complex predication and the language units in which they are realised. The relationship between events within a given situation may be sequential, transitional, simultaneous, and causal. Situation contains the following components in its structure. Location and time may be unspecified. Constructional schema of a situation:

$\begin{array}{lc}\text { Situation } & \mathrm{s} \\ \text { Event(s) } & <\mathrm{v} 1(\ldots \mathrm{vn}) \ldots> \\ \text { Arguments } & <\arg 1,(\arg 2, \ldots, \text { argn) ... }> \\ \text { Semantics } & \text { (Nexus-juncture relations) } \\ \text { Location.time } & \text { (time) } \\ \text { Location.space } & \text { (place }- \text { may be unspecified) }\end{array}$

The framework that we used to analyze the morphosyntactic linkage of constructions is the RRG framework of clause linkage (Foley \& Van Valin 1984, Van Valin 2005), specifically the Layered Structure of the Clause model. RRG describes types of clause linkage in terms of a combination of two notions, (i) the juncture or hierarchical level of the combination and (ii) the nexus or symmetry/dependency type of combination, as shown below:

Levels of juncture: units involved in complex sentences:

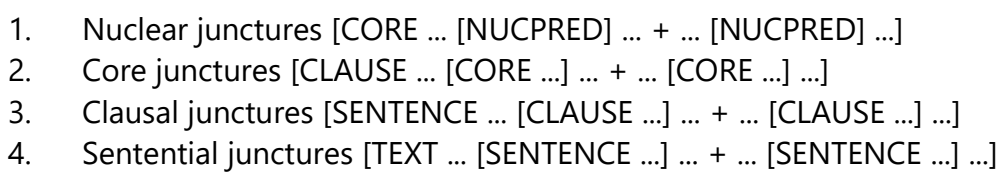

Nuclei are argument-bearing lexical items; cores are their maximal syntactic projections, dominating all their syntactic arguments. (Verbal cores thus differ from traditional verb phrases in languages such as English in that they dominate all the verbs' syntactic arguments, including the subject. Van Valin \& LaPolla (1997: 448) defined nuclear junctures are single cores containing more than one nucleus [...] taking a single set of core arguments. In a CORE juncture, [...], there is a single CLAUSE containing more than one CORE. Each core may have its own CORE arguments. In CORE junctures, the CORES must share an argument: a syntactic and semantic constituent of the matrix CORE that only has a semantic function in the CORE. In clausal junctures, "whole clauses are joined, and each clause may be fully independent of the others". The core and peripheral constituents of the two clauses are independent because argument sharing does not operate across clause boundaries.

The defining feature of core layer juncture is that there must be some 'intersection' of the two cores. This involves either the sharing of at least on core argument by both juncts, or the inclusion (embedding) of one junct as a core argument of the other. While the term of complex predicates had been explained by (Goksel 1993:14) who stated that the analysis of complex predicates involves two issues crucial to the organization of grammar: the nature of word formation and the nature of processes that affect the argument structure of predicates and clause containing them. Futhermore, Amberber, et. al. (2010:96) explained that the term complex predicate is used to designate a construction involving two or more predicational elements (such as nouns, verbs, and adjectives) predicate as a single element, i.e. their arguments map onto a monoclausal syntactic structure. Similarly, Jarkey (2015:88) explained that core juncture differs from nuclear juncture in that either predicate may have arguments that are not shared, and that arguments may intervene between the two predicates. Therefore, this study discussed an approach to compositionality and the structure toward a lexical semantic implementation of Karo language were realized in syntactic pattern.

Using language of karo tribe, the writers examined the following questions as follow: 
1. What is the characteristic of the complex predicate in Karo language based on syntactic parsing?

2. What are multiple events of Karo language that are realized by using nexus-juncture relation?

\section{Methodology}

This study used the descriptive qualitative method to reveal the nexus-juncture in Karo sentences. The data sources used were sentences containing karo sentence clauses. Data analysis techniques in this study were editing data, describing, and making conclusions. After the data was obtained, the data was classified based on the elements of complex Predicates in a tree diagram then analyzed using the RRG account of nexus-juncture relations theory by Nolan 2012; Van Valin 2005 based on literature review.

\section{Results}

An analysis of Karo Language Sentence:

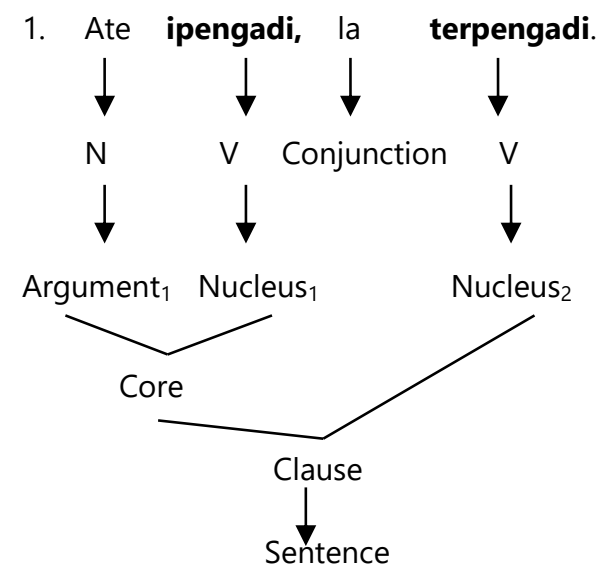

Table 1. The Nexus Juncture Relations of Karo Sentence 1

\begin{tabular}{|c|c|}
\hline Situation & $\mathrm{s}$ \\
\hline Event (s) & $<\mathrm{V}_{1}>$ PHASE-CHANGE $<\mathrm{V}_{2}>$ \\
\hline \multirow[t]{2}{*}{ Arguments } & $<$ Argument $_{1}>$ \\
\hline & $<\operatorname{Ate}_{1}>$ \\
\hline \multirow[t]{4}{*}{ Semantics } & Nuclear Juncture: \\
\hline & [Situation[Clause[Core[NU1 event-phase] [NUC 2 event] Conj. \\
\hline & {$\left[\right.$ PRED $\left._{\text {NUC1 }}\right]$ PHASE-CHANGE $\left[\right.$ PRED $\left._{\text {NUC2 }}\right]$} \\
\hline & [IPENGADI] PHASE-CHANGE [TERPENGADI] \\
\hline Location.time & Intransitive, Infinitive, Tenses \\
\hline Location.space & place - may be unspecified \\
\hline
\end{tabular}

There were two types of verbs in the sentence above, Verb 1 (ipengadi) and Verb 2 (terpengadi). The two verbs in this sentence were intransitive and have the infinitive $i$ - and ter-. Prefix $i$ - in Verb 1 (ipengadi) referred to an event or action. Prefix ter-in Verb 2 (terpengadi) indicated an event or action. Both of these verbs were basically as intransitive forms.

2. Cuba turiken ndu,
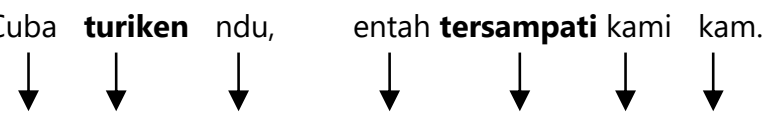


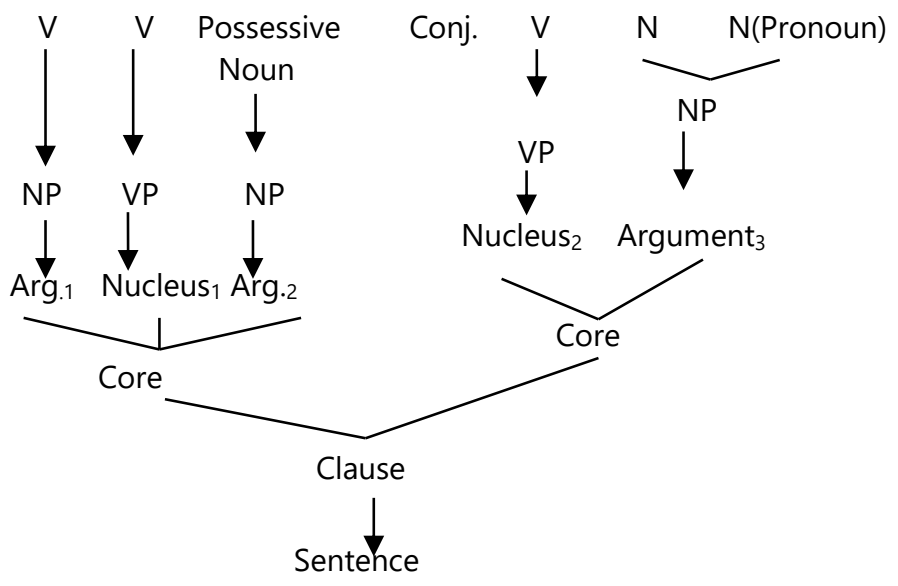

Table 2. The Nexus Juncture Relations of Karo Sentence 2

\begin{tabular}{|c|c|}
\hline Situation & $\mathrm{s}$ \\
\hline Event (s) & $<\mathrm{V}_{1}>\mathrm{SEQUENCE}<\mathrm{V}_{2}>$ \\
\hline \multirow[t]{2}{*}{ Arguments } & $<$ Argument $_{1}$, Argument $_{2}$, Argument $_{3}>$ \\
\hline & $<\mathrm{Coba}_{1}, \mathrm{Ndu}_{2}, \mathrm{Kami}_{3}, \mathrm{Kam}_{3}>$ \\
\hline \multirow[t]{4}{*}{ Semantics } & Nuclear Juncture: \\
\hline & $\begin{array}{l}\text { [Situation[Clause[Core }{ }_{1}\left[\mathrm{NU}_{1}\right] \text { Conj.]] } \\
+ \\
\left.\left[\text { Clause }\left[\text { Core }_{2}\left[\mathrm{NUC}_{2}\right]\right]\right]\right]\end{array}$ \\
\hline & [PRED $\left._{\text {NUC1 }}\right]$ SEQUENCE [PRED $\left.{ }_{\text {NUC2 }}\right]$ \\
\hline & [TURIKEN] SEQUENCE [TERSAMPATI] \\
\hline Location.time & Passive \\
\hline Location.space & place - may be unspecified \\
\hline
\end{tabular}

In the second sentence, there were two verbs, namely verb 1 (turikenndu) and verb 2 (tersampati), the two verbs in this sentence were passives verbs. The verbs turikendu and tersampati contained a prefix ter- which functioned as a passive action.

3. Piga2 kali ilompati arimo Simbelang Pinggel tapi arab kebeluhen na emdikkar terelakken ca.

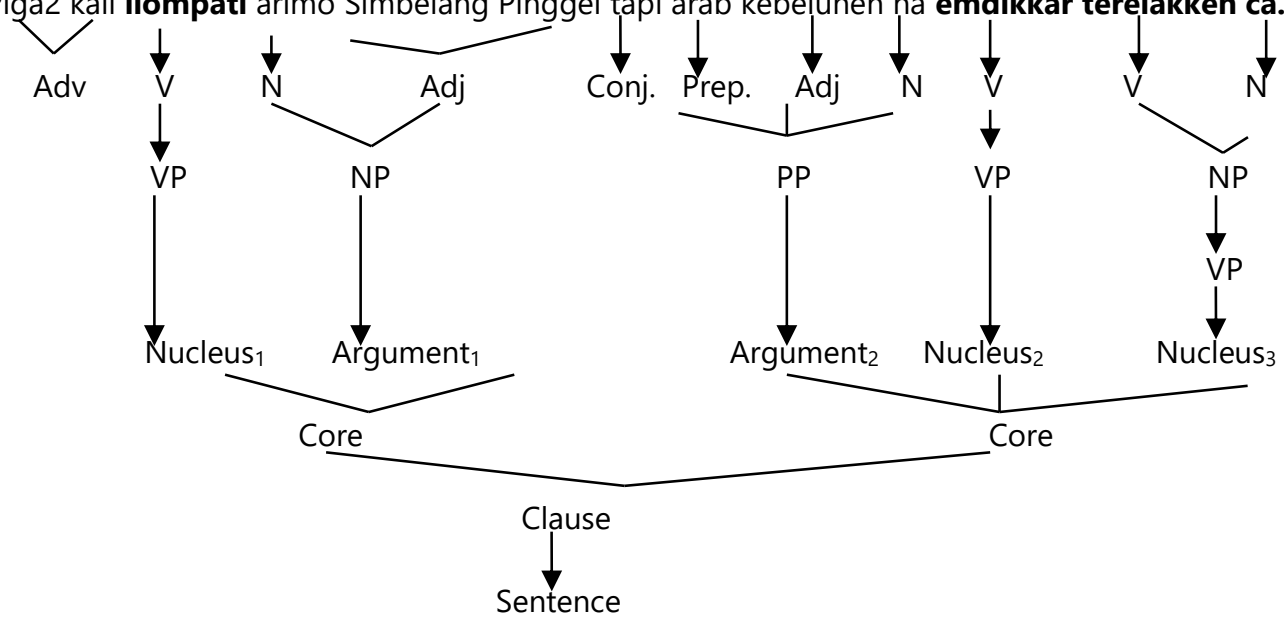

Table 3. The Nexus Juncture Relations of Karo Sentence 3

Situation $\mathrm{s}$




\begin{tabular}{|c|c|}
\hline Event (s) & $\left\langle\mathrm{V}_{1}\right\rangle$ SIMULTANEOUS $\left\langle\mathrm{V}_{2}\right\rangle\left\langle\mathrm{V}_{3}\right\rangle$ \\
\hline \multirow[t]{2}{*}{ Arguments } & $<$ Argument $_{1}$, Argument $2>$ \\
\hline & $<$ Arimo Simbelang Pinggel ${ }_{1}$, Arab kebeluhen na $_{2}>$ \\
\hline \multirow[t]{4}{*}{ Semantics } & Nuclear Juncture: \\
\hline & $\begin{array}{l}\text { [Situation[Clause[Core1[NU } 1(\mathrm{Adv})]] \\
+ \\
\left.\left[\text { Clause }\left[\text { Core }_{2}\left[\mathrm{NUC}_{2}\right]\left[\mathrm{NUC}_{3}\right] \mathrm{N}\right]\right]\right]\end{array}$ \\
\hline & $\left[\right.$ PRED $\left._{\text {NUC1 }}\right]$ SIMULTANEOUS [PRED $\left.{ }_{\text {NUC2 }}\right]\left[\right.$ PRED $\left._{N U C 3}\right]$ \\
\hline & [ILOMPATI] SIMULTANEOUS [EMDIKKAR] [TERELAKKENCA] \\
\hline Location.time & Passive \\
\hline Location.space & place - may be unspecified \\
\hline
\end{tabular}

In the third sentence, it contained three verbs; verb1 (ilompati), Verb2 (emdikkar) and Verb3 (terelakkenca). Verb 1 (ilompati) contained the prefix $i$ - which pointed out to an EVENT or ACTION. In Verb 2 (emdikar) contained the prefix em- which referred to an EVENT or ACTION. Verb 3 (terelakkenca) contained the suffix enca- which referred to an EVENT or ACTION.

4. Ise nampatisa engko merdang nderbih?

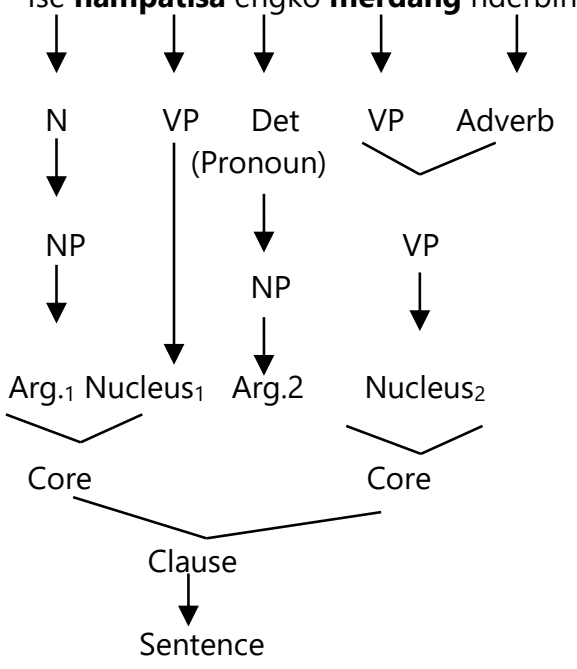

Table 4. The Nexus Juncture Relations of Karo Sentence 4

\begin{tabular}{|c|c|}
\hline Situation & s \\
\hline Event (s) & $<\mathrm{V}_{1}>$ TRANSITION $<\mathrm{V}_{2}>$ \\
\hline \multirow[t]{2}{*}{ Arguments } & $<$ Argument $_{1}$, Argument $_{2}>$ \\
\hline & $<\mid \mathrm{se}_{1}$, Engko $\left._{2}\right\rangle$ \\
\hline \multirow[t]{4}{*}{ Semantics } & Nuclear Juncture: \\
\hline & $\begin{array}{l}\left.\text { [Situation[Clause[Core }{ }_{1}\left[\mathrm{NU}_{1}\right]\right] \\
+ \\
{\left[\text { Clause }\left[\text { Core }_{2}\left[\mathrm{NUC}_{2}\right]\right]\right]}\end{array}$ \\
\hline & 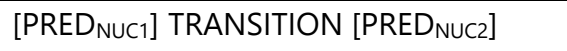 \\
\hline & [NAMPATISA] TRANSITION [MERDANG] \\
\hline Location.time & Active Verb, Transitive Verb \\
\hline Location.space & place - may be unspecified \\
\hline
\end{tabular}

In the fourth sentence, there were two verbs, namely Verb 1 (nampatisa) and verb 2 (merdang). The two verbs in this sentence were Active Transitive verbs. 
5. Asakai si enggo irungtung itamai ku sumpit.

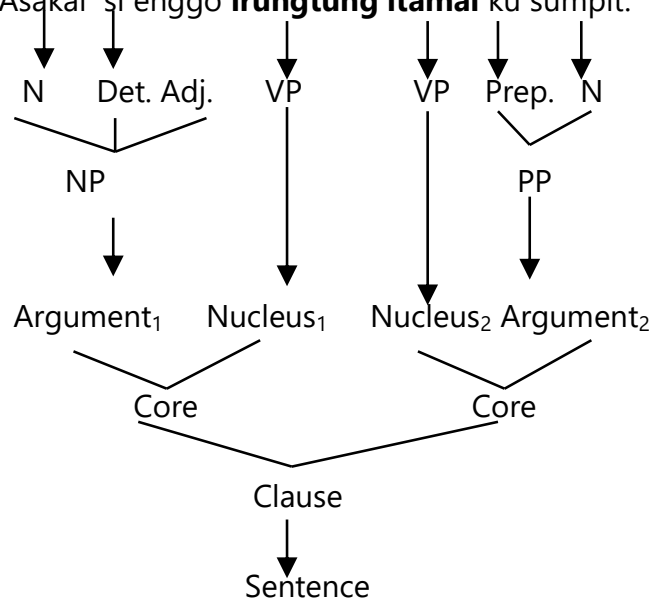

Table 5. The Nexus Juncture Relations of Karo Sentence 5

\begin{tabular}{|c|c|}
\hline Situation & $\mathrm{s}$ \\
\hline Event (s) & $<\mathrm{V}_{1}>$ TRANSITION $<\mathrm{V}_{2}>$ \\
\hline \multirow[t]{2}{*}{ Arguments } & $<$ Argument $_{1}$, Argument $_{2}>$ \\
\hline & $<$ Asakai $_{1}$, Ku sumpit $2>$ \\
\hline \multirow[t]{4}{*}{ Semantics } & Nuclear Juncture: \\
\hline & $\begin{array}{l}\text { [Situation }\left[\text { Clause }\left[\text { Core }_{1}\left[\mathrm{NU}_{1}\right]\right]\right. \\
+ \\
{\left[\text { Clause }\left[\text { Core }_{2}\left[\mathrm{NUC}_{2}\right]\right]\right]}\end{array}$ \\
\hline & [PRED $\left.{ }_{\text {NUC1 } 1}\right]$ TRANSITION [PRED $\left.{ }_{\text {NUC2 }}\right]$ \\
\hline & [IRUNTUNG] TRANSITION [ITAMAI] \\
\hline Location.time & Past \\
\hline Location.space & place - may be under unspecified \\
\hline
\end{tabular}

In the fifth sentence, there are two verbs, namely Verb 1 (irungtung) and verb 2 (itamai). The two verbs in this sentence were in the form of Past tense.

\section{Discussion}

The relationship between syntax and semantic of complex predicates could be realized by using a sentence. The tightest syntactic linkages embodied the closer semantic relations in a particular language. It could be described as the role of arguments in relation to the verb was signalled by word order. The role of argument in the saturation of a predicate was usually taken as its definition in formal semantics. Arguments were entities carrying grammatical information, the presence of which derived from the lexical conceptual structure of a predicate. Such definition indicated that the only coherent definition of an argument was one which was semantically based.

A sentence could contain more than one verb or multiple verbs and each verb must have one argument. The event could describe the activity or the state that had been done by argument, so the argument must be formed in NP. Moreover, the event may be unspecified in time and place. NP (Actor) function was a shared argument over both verbal predicates, since the term 'clause positioned at the topmost nucleus (VP) and ranged over the complete event. NP immediately interpreted as the subject or indirect object. The function of multiple verbs was to explain the event that happened in a sentence, so both verb and argument must represent the relationship between event and participant. There are two possible recipients in multiple verbs: the cause and the embedded object. Most of the complex predicates in Karo language have an embedded object. The embedded object can become the subject of a passive clause. This was how a transitive verb in any language was logically specified: a two-place predicate was a relation between individual entities, equivalently a function from an individual argument to a one-place predicate, itself a function from individuals to truth values as the example of result analysis below: 
In the first sentence, verb1 (ipengadi) and verb2 (terpengadi) described an event in a sentence. ( $N+V+V)$. Argument 1 (ate) was to describe the participant in the first clause (NP). However, in the second clause, argument1 (ate) was ellipsis and caused an embedded subject. The correlation of verb 1 (ipengadi) and verb 2 (terpengadi) was determine by a conjunction (la). The function of conjunction is carrying the meaning of lower parts of structure up at the sentence. It revealed the relationship of the two complex predicates by semantically and syntactically. One argument could represent more than two nuclei (VP), namely ipengadi (Nucleus 1 ) and terpengadi (Nucleus 2 ). The event was in the form of Phase-Change. It meant that a situation (Sentence) contained one clause, one core, and more than one complex predicates (Nucleus) in the form of semantic when it was analyzed as nuclear juncture. In Karo language, most Actors/Arguments (NP) were in the form of the embedded subject or embedded object so the meaning could be realized by using a tree diagram.

In the second sentence, the three verbs (multiple verbs) in the form of $\mathrm{V}+\mathrm{Vp}$. In the first core, it could be seen that the structure of the event $(\mathrm{V}+\mathrm{V}+\mathrm{N})$ (Cuba turiken ndu). Meanwhile, in the second core, the form of event structure of multiple verbs $(\mathrm{V}+\mathrm{N}+\mathrm{N})$ (Tersampati kami kam). Argument 1 (Cuba) could be seen in core ${ }_{1}$. Meanwhile, argument (kami) and argument $_{3}$ (kam) could be seen in core2. In other words, the participant as an actor could be realized in one core, but the core has only one event. ). The event was in the form of a Sequence. It meant that a situation (Sentence) contained two clauses, two core, and more than one complex predicates (Nucleus) in the form of semantic when analyzed as nuclear juncture.

Based on the examples, it could be described that in Karo tribes, the core in the nucleus could have appeared not only one core but two or more complex predicates and it followed by an argument with the form $\mathrm{V}+\mathrm{V}+\mathrm{N}$ and in the form of $\mathrm{V}+\mathrm{V}+\mathrm{N}$. One argument (Participant/Actor) that involved one core. It assumed that there might be one participant in two events, and there may be two participants in one event.

\section{Conclusion}

Most of the unmarked patterns for the construction of complex sentences involved combining nuclei with nuclei, cores with cores, or clauses with clauses. These were called levels of Juncture in RRG, i.e. nuclear juncture, core juncture, and clausal juncture. The importance of complex predicate is the possibility of syntactic and semantic relations between units in a juncture. The syntactic relations between units were called nucleus relations in RRG. In Karo tribes, the core in the nucleus could appear not only one core but also two or more complex predicates followed by an argument with the form $\mathrm{V}+\mathrm{V}+\mathrm{N}$ and $\mathrm{V}+\mathrm{V}+\mathrm{N}$. One argument (Participant/Actor) that involved one core. It assumed that there might be one participant in two events, and there may be two participants in one event. The writers also suggested that future research focus on how complex predicates were classified as compound verb in Karo language and determined causativization in argument structure to avoid native speakers' judgments.

Funding: This research received no external funding.

Acknowledgments: The writers would like to acknowledge Universitas Katolik Santo Thomas Sumatera Utara for the contribution in this research.

Conflicts of Interest: The authors declare no conflict of interest.

\section{References}

[1] [1] Amberber, M., Baker, B., \& Harvey, M. (2010). Complex Predicates: Cross-Linguistic Perspectives on Event Structure. Cambridge: Cambridge University.

[2] [2] Brill, I. (2007). Nexus and juncture types of complex-predicates in oceanic languages : functions and semantics. Language and Linguistics, $8(1), 267-310$.

[3] [3] Foley, William, \& Robert D. (1984). Functional Syntax and Universal Grammar. Cambridge: Cambridge University Press.

[4] [4] Goksel, A. (1993). Levels of Representation and Argument Structure in Turkish. London: University of London.

[5] [5] Jarkey, N. (2015). Serial Verbs in White Hmong. Leiden: Brill.

[6] [6] Nolan, B. \& Diedrichsen, E. (2005). Argument Realisation in Complex Predicates and Complex Events. Amsterdam: John Benjamin Publishing.

[7] [7] Van Valin \& Robert, D. (2005). Exploring the Syntax-Semantics Interface. Cambridge: Cambridge University Press.

[8] [8] Van Valin, R. \& LaPolla, R. (1997). Syntax. Cambridge: Cambridge University Press 